\title{
Newsgames: Theory and Design
}

\author{
Miguel Sicart \\ Assistant Professor \\ Center for Computer Games Research \\ IT University of Copenhagen \\ miguel@itu.dk
}

\begin{abstract}
Computer games have a long history as entertainment media, but their use for educational or political communication is relatively recent. This paper explores the use of computer games as news media. Newsgames are computer games used to participate in the public sphere with the intention of explaining or commenting on current news. The paper provides a set of concepts for analyzing newsgames, based on public service theory. The paper expands this analytical approach with a reflection on game design methodologies for creating newsgames.
\end{abstract}

Keywords: Newsgames, Serious Games, Public Service Theory, Procedural Rhetorics, Political Games.

\section{Introduction}

In November 2007, the Danish electoral campaign was at its peak. There were political messages in all mass media, from the press and television to Internet sites and social networks. But the 2007 Danish elections will be remembered as the first elections were most political parties developed and launched a computer game. ${ }^{1}$

The path from SpaceWar! to political games illustrates the cultural impact of information technologies and the Internet in Western Societies. Fast, networked computers have become as ubiquitous as television or radios, and software for game development has become easier to learn and distribute. It is a natural step to use these favorable conditions for developing games that answer to deeper needs than entertainment. Computer games can also participate in public debates, by means of their procedural rhetorics [1].

I will define newsgames as those games that utilize the medium with the intention of participating in the public debate. The ease of development and distribution contribute to the evolution of game that comment or simulate news events, understood as "the preexisting discourse of an impersonal social institution which is also an industry"[2].

1 The Danish journalist Thomas Vigild commented these games on his blog: http://blog. politiken.dk/klik/category/politik/. Political games are not new: the 2004 United States election saw the first candidate-endorsed game, Dean for Iowa (http://www. deanforamericagame.com/), and in 2005 Newsgaming.com developed Cambiemos, a game for the Uruguayan socialist party (http://www.ludology.org/my_games.html). 
The term "newsgame" lacks a formal definition applicable both for analysis and design. I will define newsgames using public service theory and concepts from computer game studies, thus providing a general framework for the analysis of newsgames.

A second goal is to present newsgames in relation to computer game design. I will reflect on methods for designing newsgames, applying the theories on value-based design by Nisembaum, Flanagan, Belman and Diamond [3] and the work on computer game rhetorics by Bogost and Frasca [4].

In this paper I will argue for computer games as a valid tool for public debates and exchanges of ideas between citizens: as a civil tool for simulation and communication.

\section{Newsgames: Theory}

Serious games are games used for different purposes than just entertainment [5]. More precisely, serious games use the rhetorics of games [6] to convey messages with intentions different than to entertain. This category potentially includes all kinds of games, from classic board and role playing games to simulations on computers.

In this paper I focus on serious computer games, as defined by Bergeron [7]: "an interactive computer aplication, with or without a significant hardware component, that: has a challenging goal; is fun to play and/or engaging; incorporates some concept of scoring; imparts to the user a skill, knowledge, or attitude that can be applied in the real world" (xvii). This meta-category encompasses all kinds of serious games. Defining newsgames requires a more focused approach.

Newsgames are serious computer games designed to illustrate a specific and concrete aspect of news by means of their procedural rhetoric, with the goal of participating in the public debate. Newsgames are ephemeral as the news they illustrate, and they often have editorial lines correspondent to the lines dictated by their parent media.

In this sense, newsgames do not cover general political topics, like September 12th [8], nor they are used for political campaigning, like Dean for America. Newsgames are designed to accompany a specific piece of news. This implies that newsgames do not have the intention of surviving in the collective memory for a long time, nor they have a replayability requirement. Newsgames illustrate and comment the news, and are as perishable as the news themselves.

Nevertheless, newsgames have the ambition of transmitting important notions about news events by means of their rhetoric. In this sense, public service broadcasting theory casts some light on how media are used to participate in the public debate. I am not implying that newsgames are public service media. Public service broadcasting theory offers a number of arguments that explain the use of traditional media for conveying news; this theory can be expanded to cover newsgames, both produced by private firms and by public corporations.

Public broadcasting is relevant because "broadcasting should have objectives other than the entertainment of viewers and listeners and the profitability of private broadcasting firms" [9]. The same applies to newsgames: they are not for direct profit, and they want to go beyond the limitations of pure entertainment, challenging their audiences to different experiences. 
Newsgames are a sub-type of political games because they do not necessarily convey a political message, but the implications of a piece of news. Any transmission of news is editorialized, but newsgames do not need to be received exclusively as political opinion pieces: "people do not normally believe that news exists primarily to influence them. They also do not believe that they consume news for the purpose of being influenced" [10]. Newsgames are a type of political games that do not have as the main goal to transmit a political idea, but to simulate certain aspects of news as relevant for an intended audience. That simulation can be political, but does not need to.

This audience is not understood as consumers, but as citizens ${ }^{2}$ that share a vision of the public interest. Denhard \& Denhard [11] define the role of public administrators as that of "building a collective, share notion of the public interest", and it is in this perspective newgames are tools for shaping the public space for debate on a specific topic.

Having citizens as target group implies that newsgames do not intend to convince people about a specific agenda related with news, but to convey a space of opinion within a space of possibility, defined as "the space of future action implied by a game design" [12]. Unlike the broader category of political games, which try to change their user's frames and ideas on specific political topics, ${ }^{3}$ newsgames "serve rather than steer", helping "citizens articulate and meet their shared interests, rather than to attempt to control or steer society in new directions" (Denhard \& Denhard, p. 553).

The number of non-steering newsgames is rather small: titles like Madrid [13] convey an ideological message, and present other perspectives on news events to the public opinion. These newsgames present a conceptual interpretation of an event that can intervene, and potentially enhance the public debate, without steering the argumentation. Madrid, for example, illustrates the collective sense of empathy the bombings in Spain created, but also reflects on the need to actively not forget about this bombings, or any bombings, so history will not repeat. These ideas are presented both in the audiovisual level, as graphics and sounds, and in a systemic way, as rules and processes the player has to interact with in order to experience the game.

This definition of newsgames provides them with a goal. Unlike political games, that present a clearly biased argumentation with the intention of shifting or reassuring the audience in their political beliefs, newsgames do not enforce directly instrumental goals. Newsgames will not change ideas, but provide arguments for engaging in discussions within the public sphere. The goal of newsgames is to address citizens more than consumers: "in that lies the real clue to the nature and purpose of great broadcasting: that it makes best sense when it represent a national and moral optimism within a society, when it suggests (...) that we can be better than we are: better served, better amused, better informed, and thus, better citizens".[14]

Newsgames have a political agenda and an editorial line, but those are presented as an open space for discussion. Political and persuasive games appeal to the partisan, newsgames appeal to the citizen. But newsgames are not, and should not be ideologically neutral. Like any other form of discourse addressed to the public, these games have an agenda, which is presented not as truth, but as arguments. Newsgames are computer games that engage in a public discussion, articulating discourses using procedural rhetoric.

\footnotetext{
2 "Serve citizens, not consumers", Denhard \& Denhard (2000), p. 565.

${ }^{3}$ Frames as defined by Bogost (2007), pp. 99-121.
} 
In 1985 the British Broadcasting Research Unit suggested eight principles that should be present in all types of broadcasted public services ${ }^{4}$. Newsgames are a different media in a different era, yet it is interesting to formulate some principles that ought to be present in newsgames. And so, newsgames (tend to) follow these principles:

- Easy, almost universal distribution: browser based games are often the vehicle for newsgaming, while downloads are more rare and less desired, since they require specific hardware configurations.

- Newsgames can have an editorial line, but they do not have political interests. Newsgames illustrate, not persuade.

- Newsgames participate in the public debate illustrating news by means of procedural rhetorics, but they do not want to steer the discussion.

- Newsgames should only refer to specific news in a specific period of time: newsgames are temporal, they do not aspire to survive longer than the news.

Newsgames are produced with the intention of participating in the public sphere with arguments that illustrate perspectives on news. Those arguments are made by means of the techniques of games: the simulation of systems by means of procedural rhetorics. Newsgames adapt the content of news to the expressive capacities of computer games, creating ephemeral games.

\section{Newsgames: Design}

Computer games are complex systems for interaction that require careful design to be engaging, balanced and operative. Game design is the craft of creating interesting gameplay with the goal of engaging players in a ludic experience. In computer game productions, most of the design is often done during preproduction, and it can take up to weeks or months to design a computer game.

Newsgames do not have that privilege: they have to be produced and launched while the news are still relevant, not only to participate in the public debate, but also for the game to have any meaning. Newsgames have very focused designs that tend to afford narrow but deep interaction, playing with game design conventions and genres that allow for faster implementations.

But before detailing the design constraints and paradigms for creating newsgames, it is necessary to mention that newsgames, like any other computer game, can have embedded values in their design, as Flanagan et al. have argued [3]. Any game presents a set of values hardcoded in the system design, and presented to players as affordances and constraints [15]. Most of these do not have explicit ethical, political or social goals: commercial games do not put in the center of its experience the expression of interesting dilemmas by means of the interaction with their game system, even though they can be experienced and analyzed as moral or political objects.

Political games and newsgames, on the other hand, make these affordances and constraints an explicit part of their design. Newsgames use these affordances to

4 These principles are: geographic universality; funding by the (viewer/listening) audience,; independence from government or vested interests; concern for national identity and community; catering for all interests and tastes; catering for minorities; quality of programming; and creative freedom for program makers (Brown: 1996, p. 4; see also Tracey: 1998, pp. 26-32). 
convey they meaning of the news, to illustrate their positions and to communicate to the player.

This is, the first design criteria for newsgames: the message should not be hidden. The game as a rhetorical device must be aware of its interpretation of the news, which should also be made explicit and clear to the player. Political and propaganda games can hide the fact that they limit player interaction with expressive purposes; newsgames, in order to be editorial but not steering, need to clearly communicate these design conditions to the player.

The main challenge that designing newsgames poses is translating the content and relevance of news into interesting gameplay that can be experienced by players. This game system has to steer and illuminate the news it is addressing. This means that the game adapts the elements of the news to playable elements that are relevant for understanding the simulated.

News, for game design, should be understood as design constraints. Designing newsgames is translating those constraints into game rules, mechanics, and challenges. Game rules are the basic conditions for the game, including the end state or the winning condition, plus the limits of the gameworld and/or the game experience. Game mechanics are the designed actions players can take within that game experience. In a newsgame, the main news sets both the rules, specially in terms of the winning condition, and the game mechanics, or how the player interacts with the gameworld.

In Madrid, for example, players only have one mechanic available: to light candles. They invoke it by clicking with the mouse on the candles, and the rules of the game state that if there is no player input after a certain time, the game loop will stop and the endscreen will be presented. The game has no winning condition, it only has rules that determine both the endstate and the losing condition. By giving players an neverending task, Madrid conveys its message: memory is an active effort, and in the wake of a tragedy, we must also act to remember. This message is conveyed by manipulating game mechanics and conventions, such as the absence of a winning condition.

The mode in which news are translated into game systems determines the editorial line of the game, as it conditions which elements are going to be simulated and which are left out. The ideology of a newsgame, then, can be found in the way the original topic of the news has been translated into the game system, and how that system is presented to a player by means of afforded and constrained mechanics. Returning to Madrid: the game translates the difficulties of collective mourning and historic memory by forcing players to a perpetual action. Players are encouraged to remember, even though there is no victory; players are also punished for their passitivity. Unlike September 12th, which could only be won by not playing, Madrid can only not be lost by playing it.

Since production cycles are rather brief, newsgames have very basic game mechanics inspired, or directly copied from classic games. Far from being a problem, this is an advantage for newsgame design. For an game, it is fundamental that players understand the principles of play. In more conventional games, the learning curve is steep and requires some time. But newsgames' players need to be presented from the outset with elements they find familiar. Typically, players of newsgames will not use much time learning new controllers or mechanics, so the access point has to be relatively well know for the average target group user. Thus the use of game conventions: appealing 
to the player repertoire [16] eases the access and consumption of the game by the intended audience.

On the other hand, newsgames appeal to reflective players that can suspend their own immersion in the game, and see its inner workings as a piece of editorial content. In a phenomenological sense, newsgames requires players to experience play and to experience the experience of play: players need to understand from a meta-level what interaction and simulation means for a particular game; they need to be alienated from conventions so that the message of the game is communicated. For example: This player "alienation" can be done my means of transforming the rules and the game mechanics of a game, as Madrid does with the absence of a winning condition.

The rules of a game are designed to create an satisfactory winning condition that is challenging to achieve, and every element of those rules is optimized to create a specific ludic experience in the player. In newsgames, on the other hand, rules and mechanics are the systemic embodiment of the boundaries of the editorial line. Rules are a fundamental part of the meaning of a game as a newsgame. This means that, in newsgames, rules are the opinion: the boundaries where play takes place, those that decide what is simulated, and how. Game mechanics communicate the editorial line of a game by funneling player agency towards a specific type of behaviors relevant for understanding the message of the game. The goal of the newsgame designer is to create a set of mechanics that allow interaction with the world, but are sufficiently opaque so players reflect about the meaning of their actions.

In summary, newsgames translate editorial lines into game mechanics and rules. Salen and Zimmerman have pointed out that computer games tend to obscure the player from the inner workings of the game system. ${ }^{5}$ This black box technique blinds players from the algorithimical relations between input and output, and is often used to enhance the alleged immersive capacities of the game, making players focus exclusively in their agency and presence within the gameworld.

Newsgames are more keen on showing their inner system. Newsgames require reflective players that can see the semantics of the game mechanics and rules. To attract and help these players, newsgames present either self-referential mechanics, or mechanics designed for breaking the players' expectations. They key element in newsgame design is not only to translate the news into a game, but also to make players realize the editorial line of the game.

\section{Conclusion}

In this paper I have argued that computer games, thanks to its unique rhetorical capacities, can be effectively used to participate in the public debate. Newsgames are an editorialized, not persuasive genre of political games or serious games, developed in connection to a specific piece of news.

Newsgames are a hint of the future of computer games, not in terms of technological development, but in their role and influence in our culture. Not using computer games for engaging, and even creating public debate to the illustrated digital public is missing an opportunity for making history with a genre. The use of computer games

\footnotetext{
${ }^{5}$ See Salen and Zimmerman (2004), pp. 88-89.
} 
to illustrate and discuss must be an imperative in the future developments of the society of information.

\section{References}

[1] Bogost, I.: Persuasive Games. The Expressive Power of Videogames. The MIT Press, Cambridge (2007)

[2] Hartley, J.: Understanding News. Routledge, London (1982)

[3] Flanagan, M., Nissembaum, H., Belman, J., Diamond, J.: A Method for Discovering Values in Digital Games. In: Situated Play. Proceedings of DIGRA 2007 Conference, pp. 752-759 (2007)

[4] Frasca, G.: Videogames of the Oppressed: critical thinking, education, tolerance and other trivial issues. In: Wardrip-Fruin, N., Harrigan, P. (eds.) First Person, New Media as Story, Performance, and Game. The MIT Press, Cambridge (2004)

[5] Abt, C.: Serious Games. University Press of America, New York (1970)

[6] Sutton-Smith, B.: The Ambiguity of Play. Harvard University Press, Cambridge (1997)

[7] Bergeron, B.: Developing Serious Games. Charles River Media, Hingham (2006)

[8] http://www.newsgaming.com/games/index12.htm (September 12)

[9] Brown, A.: Economics, Public Service Broadcasting, and Social Values. The Journal of Media Economics 9(1), 3-15 (1996)

[10] Gunther, A.C., Thorson, E.: Perceived Persuasive Effects of Product Commercials and Public Service Announcements. Communication Research 19(5), 574-596 (1992)

[11] Denhard, R.B., Denhard, J.V.: The New Public Service: Serving Rather Than Steering. Public Administration Review 60(6), 549-559 (2000)

[12] Salen, K., Zimmerman, E.: Rules of Play. The MIT Press, Cambridge (2004)

[13] Madrid, http://www.newsgaming.com/games/madrid/

[14] Tracey, M.: The Decline and Fall of Public Service Broadcasting. Oxford University Press, Oxford (1998)

[15] Norman, D.: The Design of Everyday Things. Basic Books, New York (1988)

[16] Juul, J.: Half Real. Videogames between Real Rules and Fictional Worlds. MIT Press, Cambridge (2005) 